\title{
JUNTAS VECINALES DE EL ALTO \\ Memórias Campesino-Sindicais na \\ Constituição do Protagonismo Social
}

\author{
Marcelo Argenta CÂMara
}

R E S U M O Este artigo analisa a constituição dos movimentos sociais urbanos na municipalidade de El Alto, na Bolivia, enfatizando os aspectos de re-territorialização das práticas sociais aymarás e mineiras no espaço urbano boliviano. A partir desta análise procura-se destacar a importancia de tais movimentos para os processos políticos vividos naquele pais ao longo da última década, destacando-se, em especial, os acontecimentos do ano de 2003 conhecidos como a Guerra do Gás. O trabalho teve como metodologia a pesquisa participativa e sua construção prioriza os depoimentos obtidos junto aos próprios integrantes dos movimentos analisados. Nas consideraçôes finais destaca-se a importância de uma análise que abranja as diferentes perspectivas mencionadas aqui para uma compreensão efetiva da ação social na Bolivia.

P A L A V R A S - C H A V E Aymarás; Bolivia; El Alto; Juntas Vecinales; mineiros; movimentos sociais; urbanização.

\section{INTRODUÇÃO}

Recentemente, em meio ao período em que este artigo vinha sendo redigido (26/12/10), o governo boliviano emitiu o Decreto Supremo 0748, que autorizava uma série de aumentos - entre os 22 e os $99 \%$ - sobre os preços dos combustíveis líquidos. A medida, cujas justificativas afirmadas pelo governo não cabem no escopo deste trabalho, encontrou forte reação popular devido aos impactos que geraria sobre a economia real não aquela dos números macro, dos índices incompreensíveis, mas a vivida pela maioria da população que sofreria na pele os aumentos generalizados de preços que surgiriam em progressão geométrica - e uma série de mobilizações e protestos se deram ou se organizaram nos dias que sucederam a emissão do decreto. E em meio às vozes que se alçaram para protestar contra o gasolinazo - nome pelo qual o decreto ficou conhecido - uma carta emitida por um grupo de ativistas avisava: "Como em 2003, El Alto derrubará as políticas antipopulares!".

A afirmativa, em tom de ameaça, nos recorda o papel fundamental exercido pela cidade de El Alto e, em especial, pelo movimento social surgido de suas ruas e bairros para os processos políticos ocorridos no país ao longo da última década. A Federación de Juntas Vecinales de El Alto - Fejuve - entidade matriz que reúne as mais de 500 juntas vecinales existentes ao longo dos 9 distritos em que se divide o município, tornou-se um referente de luta e mobilização social cuja repercussão ultrapassou as fronteiras nacionais. Não é possível explicar toda a sucessão de acontecimentos políticos que permitiram a chegada de Evo Morales à presidência do país, sem dedicar parte dessa análise ao movimento altenho, cujas manifestações em momentos-chave como os acontecimentos do ano 2003 - a chamada "Guerra do Gás" - foram peças cruciais na construção do movimento 
político que permitiu a derrocada dos governos neoliberais que se haviam instalado na Bolívia na década de 1980.

As juntas vecinales, que em uma aproximação semântica poderíamos traduzir como "associações de moradores" ou "associações de bairro", são uma das formas de associação coletiva mais tradicionais na Bolívia e estima-se que existam mais de 7.200 em todo o país. Suas origens coincidem com o próprio processo de urbanização do país ao longo do século XX, no qual muitos dos bairros nas principais cidades foram erguidos em processos autogestionados nos quais a solidariedade e o esforço coletivo foram essenciais.

Dentro deste quadro comum a todo o país, a cidade de El Alto destaca-se em razão de sua posição geográfica: localizada no altiplano andino, às margens do vale no qual se encontra a cidade de La Paz, El Alto é o ponto de ligação entre as comunidades aymarás dispostas ao longo do altiplano e a sede do governo boliviano, além de se configurar como o principal destino das populações migrantes do espaço rural andino. Tais condições conferem aos bairros de El Alto uma característica especial, pois neles se reconstroem diferentes territorialidades - em especial as territorialidades aymarás e mineiras - em meio ao espaço urbano, fazendo com que a mobilização social alteña não possa ser analisada apenas sob um viés classista, sendo essencial uma interpretação geográfica a partir da compreensão das territorialidades andinas e de sua des-re-territorialização.

Este trabalho apresenta os resultados da pesquisa realizada ao longo do ano de 2008 dentro do "Programa de Becas CLACSO-ASDI", na linha de pesquisa "Cultura, Poder e Contra-hegemonia". Sua proposta é analisar a importância da mobilização social alteña para os processos políticos recentes na Bolívia, considerando para isso a questão da retomada das formas de gestão territorial aymarás na constituição das juntas vecinales.

Dentro deste propósito, dedicamos parte da análise aos acontecimentos do ano 2003, provavelmente o momento em que a importância da cidade de El Alto para a política nacional boliviana mostrou-se com maior nitidez.

A metodologia aplicada na construção desta investigação incluiu trabalhos de campo (pesquisa participativa); sendo assim, parte de nossa construção textual está baseada em

1 Mantivemos a grafia no original, por considerarmos que a tradução ao português não expressa a carga semântica que este termo adquire quando mencionado em relação às organizacões de bairro em El Alto. Consideramos que, naquele contexto, vecino já adquire o status de uma categoria social específica, e não uma mera relação de proximidade residencial.

2 Segundo dados do último censo (INE, 2002), enquanto a taxa de crescimento intercensos (1992-2001) para a Bolívia foi de 2,74\%, para a municipalidade de El Alto esta taxa foi de 5,10\%. 0 município é o que possui a maior taxa migratória de todo o departamento (no país ela só é comparável à do departamento de Santa Cruz). depoimentos colhidos com dirigentes de juntas vecinales, vecinos ${ }^{1}$ e lideranças de movimentos sociais indígenas (as quais denominaremos autoridades).

\section{EL ALTO: CONSTITUIÇÃO DA CIDADE AYMARÁ}

O município de El Alto nasceu, a princípio, como periferia da sede do governo boliviano e teve sua emancipação em 6 de março de 1985. De lá para cá se tornou a terceira maior cidade do país em termos populacionais: segundo o censo de 2001, a cidade contava com mais de 600 mil habitantes, representando um crescimento de 5\% anuais em relação ao censo anterior (1992), a maior taxa de crescimento populacional de todo o país (Garfias; Mazurek, 2005). ${ }^{2}$

As migrações cumprem um papel importante na constituição alteña, a "Babel das migrações" (García, 2005), cidade que sintetiza, em seus bairros, experiências de diversos setores e regiôes do país. A questão migratória é assim interpretada por uma autoridade:

Se no altiplano as pessoas comem, se lá se produz e se geram ingressos econômicos, já não haverá migração, já não haverá os cinturões de pobreza que vemos neste momento e que dão uma má aparência de uma Bolívia que não tem nada. Mas o Estado e os governos departa- 
mentais nunca tiveram políticas de desenvolvimento. (...) Assim, lamentavelmente, nos últimos trinta anos a migração da área rural para a parte urbana - não somente no departamento de La Paz - tem sido bastante significativa. Isso devido ao pouco apoio ou respaldo dos governos departamentais e do governo central para conseguir o desenvolvimento ou melhorar as condiçôes de vida na área rural. (depoimento da autoridade FTCLPTK; ${ }^{3}$ tradução livre)

Formou-se assim uma cidade de constituição aymará na qual 50,68\% da população afirmam falar o idioma, e 74,25\% definem-se como pertencentes a essa nacionalidade. É uma cidade jovem em sua existência formal, mas que se orgulha de ostentar uma história que remonta aos primeiros anos de ocupação colonial espanhola, e junto a ela, uma longa memória de lutas sociais indígenas. Foi a posição geográfica do sítio de El Alto em relação à cidade de La Paz que justificou sua ocupação (e o perfil dessa ocupação), e que deu à população da cidade um recurso estratégico por ela apreendido e largamente utilizado. ${ }^{4} \mathrm{Da}$ região conhecida como La Ceja, (em tradução livre, algo como a sobrancelha de El Alto), a borda por onde a cidade vigia La Paz, a sede do poder estatal boliviano projeta-se no horizonte em uma visão espetacular, observada de cima pela cidade que fica "en el alto".

Essa posição estratégica privilegiada permitiu que, em 1781, Julián Apaza Nina - o mítico Tupaj Katari -, sua esposa Bartolina Sisa e sua irmã Gregoria Apaza, alguns dos maiores ícones das lutas aymarás na Bolívia, compusessem ali seus quartéis indígenas em um cerco de mais de quatro meses à cidade de La Paz; em 1899, na chamada Guerra Federal, sob a liderança do aymará Pablo Zarate Willka, foi impedido o avanço das tropas federalistas sobre a cidade; e em 1952, foi ali que se consolidou a revolução (Mamani, 2005a).

Hoje, os indicadores de pobreza da cidade mostram o resultado de seu peculiar processo de formação. De sua população total, $66,45 \%$ são considerados abaixo da linha de pobreza, e destes, 17,45\% abaixo da linha de indigência. Dos índices de saneamento básico, destacam-se 36,66\% da população sem acesso à coleta de esgotos, e mais de 50\% daqueles com acesso à água encanada o têm fora do espaço residencial (terreno ou fontes coletivas). A percepção dessa situação de carência, aumentada pela própria inépcia das administrações estatais frente às necessidades do município, é fator importante no processo de conscientização e mobilização. A criação da infraestrutura necessária para o acesso aos serviços básicos foi obra dos próprios moradores, o que resultou no surgimento das primeiras juntas vecinales na década de 1950, que recriavam, em meio urbano, as experiências comunitárias advindas do meio rural andino:

No desenvolvimento das organizações urbanas de El Alto, as tradiçōes organizativas que provinham da área rural tiveram uma forte influência, já que, ante o abandono do Estado, (...) os migrantes tiveram de reatualizar e urbanizar o conjunto de suas instituições associativas agrárias a fim de poder construir suas casas, obter iluminação pública... (etc.). (García, 2005, p.591; tradução livre)

Esse processo é parte de uma construção identitária que transparece em depoimentos:

El Alto foi uma cidade totalmente menosprezada desde que surgiu. Nunca foi atendida em absolutamente nada. E El Alto, como é majoritariamente aymará, tem seus próprios costumes, seu próprio sistema (...) autogestionários, se fazem trabalhos comunitários. Por exemplo: para abrir uma rua ou uma vala num bairro, todos os vizinhos saem e trabalham por turno, é um trabalho comunitário, (...) uma construção dos próprios altenhos. (...) desde (...)
3 Federação de Trabalhadores Camponeses do Departamento de La Paz - Tupaj Katari.

4 Lembrando que o espaço só é efetivamente um trunfo quando assim utilizado para influenciar nas relações sociais. 
5 A lógica andina se expressa por meio de uma série de princípios fundamentais que são a base para suas manifestações materiais, dos quais destacam-se os princípios da complementaridade e da reciprocidade. Para aprofundamento nesse tema indicamos o trabalho de Estermann (2006).
1997, 1998 se começou a construir (...) com um investimento mais forte (...) da prefeitura de El Alto. Porque o que se fazia anteriormente, nas zonas, (...) alguns vecinos chegavam com algum projeto, digamos, somente material, matéria-prima, pedra, e os vecinos começavam a trabalhar, a empedrar as ruas, as calçadas. Nos entregavam e nós trabalhávamos. É uma construção do altenho. (depoimento de vecino, El Alto; tradução livre)

A re-significação das memórias de longa duração andinas em meio urbano é fundamental para compreender o papel desempenhado pelas juntas vecinales enquanto entidades propulsoras da mobilização social em El Alto. Os laços herdados de uma cultura comunitária e a adoção de uma série de práticas baseadas nos preceitos da complementaridade e da reciprocidade ${ }^{5}$ foram essenciais à própria construção da cidade e são experiências transmitidas às geraçóes que, ainda que eventualmente despercebidas em momentos de "normalidade", se fazem sentir quando dos momentos de conflito. Somado a isso, a própria ligação permanente dos altenhos com suas raízes andinas reforçam laços de solidariedade entre esses dois mundos (rural e urbano), mais distintos na aparência do que na realidade. Reunindo as práticas herdadas das tradições das quais se originam os moradores da cidade, El Alto as re-territorializa em um mosaico construído a partir de experiências mineiro-sindicais e campesino-aymarás.

O seguinte depoimento é bastante ilustrativo deste processo em que se associam a percepção da necessidade com a autogestão como estratégia:

Primeiramente, (...) de acordo a nossas necessidades. Veja bem: eu sou vecino aqui em El Alto há aproximadamente 60 anos, quando a população era muito mínima (e) a água era proporcionada através da empresa de trens que funcionava (aqui). (...) Tínhamos necessidade desses serviços, e como a população ia crescendo nos organizamos em grupos de amigos e logo vecinales, e nos propusemos a fazer alguma coisa. (...) Então veio um momento de mobilizações para que o governo ou o Estado através de suas instituições nos proporcionasse (os serviços de que necessitávamos). De alguma maneira chegamos a atingir alguns desses objetivos, mas não totalmente. Acredito que fizemos isso politicamente, mas não de forma partidária, e sim coletiva ou comunitária. Diria que é assim, porque as necessidades sempre incitam algumas ações (...). Muitas vezes nos reuníamos entre jovens, porque os mais velhos trabalhavam, e nos organizávamos para algum serviço para a casa, transportando água de uma torneira ao domicílio, algumas coisas (...). Certo dia em que nos encontrávamos no campo, jogando bola, e aí entrávamos em acordo sobre o que poderíamos fazer para sanar nossas necessidades mais básicas”. (depoimento de vecino, El Alto; tradução livre)

\section{Federação de Juntas Vecinales: Matrizes de Organização Socioterritorial} URBANA

As juntas vecinales estão reunidas sob um único ente-matriz que é a Federação de Juntas Vecinales de El Alto - Fejuve, que é assim definida nas palavras de uma liderança:

A Fejuve é uma organização que agrupa as mais de 575 juntas vecinales ou bases. São organizações que se encontram em distintos lugares e esses bairros (...) são representados por presidentes de zona; o conjunto desses presidentes de zona faz uma deliberação aqui na Fejuve para tomar decisóes muito concretas, ou propostas diretas. (...) Se não somos escutados diretamente temos que baixar novamente ao ampliado de presidentes e dizer-lhes: 'olha, até 
o momento (...) não fomos escutados, agora qual o passo a seguir?’. E aí (...) os presidentes tomam a decisão de acionar mecanismos de protesto, sair pela força. (depoimento de vecino, El Alto; tradução livre)

Outro depoimento destacava a importância da questão vecinal para a coesão obtida em torno à entidade:

Isso (...) engrandece a Fejuve, porque aqui em El Alto todos somos vecinos, (...) a única maneira de se fazer escutar é de vecino a vecino, (...) e essa é a representatividade com a qual joga a Fejuve, porque acolhe também as demandas de cada um dos vecinos e das organizaçôes sociais através dessas demandas. (depoimento de vecino, El Alto; tradução livre)

Na prática a Fejuve atua como uma federação de "microgovernos de bairro" (Mamani, 2005b). Ela existe oficialmente desde 1979, herdeira das primeiras organizações de juntas de vecinos surgidas em El Alto. É nela que são expostas, diretamente, as necessidades de cada junta, especialmente em relação a problemas de desenvolvimento urbano, e se busca, por meio da unidade e da ação direta, encontrar os mecanismos que possibilitem a solução desses problemas.

O papel da entidade acabou ultrapassando, em muito, a função original de administração dos problemas urbanos. A proeminência de El Alto na vida política boliviana atrai a atenção sobre a Fejuve enquanto um dos principais canais de interlocução junto à população alteña. A Federação logra alcançar uma projeção que toca diretamente no cotidiano, no espaço vivido de seus comunários, possuindo assim um poder de convocatória invejado por todo e qualquer partido político boliviano - ainda que a entidade tenha como padrão a não adesão oficial a qualquer programa de partido, mantendo assim sua autonomia decisória.

Aqui, a questão que se abre é: como uma entidade cuja finalidade é basicamente a gestão de infraestrutura urbana torna-se um referencial político em lutas nacionais cujas demandas projetavam-se muito além da escala local, como ocorreu com a "Guerra do Gás"? Esse era, em outros termos, o questionamento surgido em depoimento:

Porque tampouco estamos com uma luta para El Alto. Por acaso é em El Alto que está o gás ou o petróleo? Está em Tarija e em Santa Cruz, os lugares mais reacionários! (...) Mas aqui em El Alto já havia essa visão e, mais ainda, foi pelo neoliberalismo que se deram conta. (depoimento de vecino, El Alto; tradução livre)

Essa política transescalar tem suas origens advindas diretamente das bases. Nelas, o papel exercido pelas juntas vecinales é fundamental, por ampliar as possibilidades de discussão de temas mais abrangentes:

Nesse processo que vem desde o ano 2001 (...) se veio discutindo a situação política do país nas juntas vecinales. (...) À parte de tocar pontos (...) concernentes aos serviços básicos como água, luz e outros, (...) também se (...) inseria na ordem do dia das juntas vecinales de uma determinada zona um ponto que tínhamos que discutir: a situação política, isto é, a conjuntura política que se vivia ou que se vive no país. Então (...) se analisava estes temas e aí se recorria as necessidades que os vecinos de El Alto tinham, especificamente. (depoimento de vecino, El Alto; tradução livre) 


\section{A GUERRA DO GÁS - CONFLITO DE TERRITORIALIDADES}

Tomamos, a partir daqui, a referência à Guerra do Gás para a análise da composição de um entre os grandes momentos de mobilização popular ocorridos em anos recentes na Bolívia no qual o protagonismo da população alteña foi crucial. Os motivos que nos levam a esta escolha específica referem-se aos seguintes pontos: (a) foi a primeira mobilização a ter como resultado a renúncia de um presidente da República após a retomada da democracia representativa no país; (b) os acontecimentos tiveram como epicentro a cidade de El Alto, a principal experiência de confluência das distintas memórias de resistência - aymarás e mineiras - em meio à urbanidade, um mosaico de distintas culturas em permanente efervescência; (c) o gás, enquanto recurso natural passível de exploração/ exportação, carrega consigo uma série de memórias e simbologias que se fizeram presentes ao longo do conflito, além de explicitar as diferentes visões e projetos de país propostas pelos grupos opositores.

A referência ao gás que se faz na denominação daqueles acontecimentos se deve ao fato que, em outubro de 2003, um conjunto diversificado de demandas ganhou unidade em torno da questão, discutida naquele momento, de um projeto de exportação do gás natural boliviano para os Estados Unidos através de um porto chileno. A denominação guerra - o que para alguns vecinos é um eufemismo, preferindo a denominação "massacre" - se deve em especial ao fato de que, em determinado momento do conflito, uma brutal repressão militar sobre a população mobilizada em bloqueios de ruas em El Alto levou à morte de cerca de 70 pessoas, em uma das maiores tragédias já ocorridas em tempos recentes no país.

Em princípio, aqueles acontecimentos não se referiam apenas às demandas relativas ao recurso gás, mas foi a partir das questôes relativas à sua exploração suscitadas ao longo da discussão daquele projeto que houve a capacidade de reunião e articulação de diferentes demandas em torno de uma causa comum. Ao longo de quase quatro meses de mobilizaçôes, foram diversos os temas que suscitaram manifestações que se uniriam gradativamente até detonarem uma complexa série de acontecimentos que levaram a situação a um ponto de posições extremadas e de inviabilidade de diálogo. A cada momento temporal que se avançava novos atores surgiam em cena, novos espaços se somavam ao conflito, em uma inédita construção de solidariedades que expunha a complexidade presente no cenário boliviano.

6 A perda territorial que se reveste de consequências mais traumáticas para o país é a que se deu para o Chile, com a perda da saída para - Pacífico na guerra entre os dois países ocorrida entre os anos 1879 e 1884 , condenando a Bolívia à mediterraneidade e adicionando graves dificuldades a seus interesses de exportação.

\section{Memórias Do GÁs}

A descoberta de reservas de 47 trilhões de pés cúbicos (TCF) de gás natural, no ano 2000, havia elevado as reservas do país a 54,9 TCF, colocando-o em condiçōes privilegiadas de ingresso no mercado de recursos energéticos. O projeto de exportação do gás boliviano era conduzido pelo consórcio internacional Pacific LNG, formado por RepsolYPF, British Gas e British Petroleum, e previa a comercialização do gás natural liquefeito (GNL) para a empresa SEMPRA, estabelecida no México e responsável pelo abastecimento energético do estado da Califórnia, nos Estados Unidos. Porém, a questão que cercava o projeto de maior polêmica era a intenção de realizar a exportação do gás através de um porto chileno, possivelmente na mesma faixa de litoral perdida pelos bolivianos na guerra com aquele país. ${ }^{6}$ 
O projeto de exportação do gás entrava, assim, na pauta de discussões políticas nacionais e reavivava memórias de longa duração que recordavam o papel dependente desempenhado pela Bolívia ao longo de toda a sua história: um país que apesar de toda a riqueza de recursos naturais amargava índices de extrema pobreza e que assistia à possível confirmação de um novo projeto exportador que lhe extrairia um recurso ao qual os próprios bolivianos tinham escasso acesso; que reavivava o trauma da perda do litoral e de todas as suas consequências para a economia boliviana e que, além disso, trazia para a pauta de discussōes a presença dos Estados Unidos, destino final do GNL, país largamente reconhecido pelos movimentos sociais como imperialista e corresponsável pelas agruras vividas no continente. Igualmente, a ausência de um projeto de tons nacionalistas de industrialização do gás em território boliviano, frente a um governo que tratava o projeto da Pacific LNG como inevitável, expunha as nítidas distâncias que separavam governo e população em suas visões de país, e criavam o tópico que acabaria por aglutinar as distintas mobilizações que naquele momento o sacudiam.

Ressaltemos, também, que naquele momento - setembro de 2003 - El Alto se via envolvida em uma luta particular, mas cuja mobilização de alguma forma já serviria como preparação às exigentes mobilizaçóes do mês seguinte. A prefeitura municipal havia proposto, em meados de agosto, um recadastramento das habitações no município, em formulários batizados "maya" e "paya" (respectivamente, um e dois em aymará). ${ }^{7}$ O rechaço ao recadastramento havia sido unânime entre os altenhos, uma vez que era compreendido como uma estratégia para elevar a carga de impostos a partir do aumento da cobrança individual sobre as melhorias feitas pelos moradores em suas residências (Mamani, 2005a).

Assim sendo, havia uma mobilização relativa a um tema especificamente altenho que teve início no dia 8 de setembro, com uma paralisação geral de 24 horas contra os mencionados formulários. A essa manifestação se somariam os estudantes universitários da Universidad Pública de El Alto (UPEA) - reivindicando a autonomia da Universidade, que até aquele momento era um campus avançado da Universidad Mayor de San Andrés (UMSA) de La Paz, da qual dependia em todos os quesitos, desde recursos financeiros, até a própria criação e/ou administração de novos cursos.

As paralisações em El Alto, com o bloqueio da autopista que une a cidade a La Paz e as marchas que descem pela mesma via para protestar junto à sede do governo, são elementos que devem ter sua importância destacada: concentrações multitudinárias que irrompem no centro de La Paz desde sua principal via de ligação com as demais regiôes do país. Igualmente, há o peso representado por essas marchas sobre a população de La Paz, pelo reconhecimento constante do poder exercido pela presença permanente de El Alto a vigiar-lhes desde as bordas do altiplano.

El Alto ainda assistiria a uma trégua quando, ao final de dois dias de uma bemsucedida paralisação geral decretada pela Fejuve, o prefeito decidiu pelo cancelamento dos formulários Maya/Paya. Há uma análise sobre a importância daquele momento para a sequência das mobilizaçóes:

Eu creio que o "Maya-Paya" foi a primeira experiência na qual El Alto reconhece seu poder de domínio territorial. (...) Então a Fejuve começa aí, pela primeira vez, a gerar comitês de organização. Do comitê executivo se enviavam delegados a cada distrito, ou seja, se distribuíam territorialmente para dar informação para a gente de base, de distrito, dirigentes. (...) A ideia de bloquear o aeroporto, (...) a distribuição dos distritos para bloquear todos os acessos
7 É interessante notar que a prefeitura se apropria de uma denominação aymará como forma de aproximação com a população local, porém utilizando-a na direção contrária dos interesses desta. 
à cidade de La Paz. É a primeira experiência de articulação territorial de luta. (depoimento de vecino, El Alto; tradução livre).

Em meio a esse cenário, uma brutal repressão ocorrida contra bloqueios de estradas por comunidades camponesas no altiplano se fez ecoar em El Alto, como nos mostra um depoimento:

Havia uma solidariedade com companheiros das distintas províncias do setor do altiplano que estavam em um bloqueio de caminhos e posteriormente foram massacrados, com muitos mortos. E a indignação de El Alto: não podíamos estar à margem, porque muitos de nós viemos desses lugares, migramos desses lugares, então eram nossos próprios irmãos, tínhamos que estar com eles. (depoimento de vecino, El Alto; tradução livre)

Aqui cabe destacar que os bloqueios de estradas no altiplano e em outras regiōes vizinhas a La Paz, em resposta às diretivas das lideranças aymarás, têm consequências nefastas para a sede do governo boliviano, pois são estas regióes que abastecem a cidade de produtos hortifrutigranjeiros. A escassez de alimentos se fez perceber nos mercados de La Paz, refletindo em alta dos preços e gerando intranquilidade.

No começo de outubro as organizaçõos alteñas decidiram por uma paralisação geral de prazo indefinido até que as demandas fossem escutadas. A participação dos altenhos no protesto, ainda que pudesse não ter sido unânime em todos os setores da cidade, era suficiente para efetivamente inviabilizar os acessos à La Paz, onde a situação pelo desabastecimento era cada dia mais grave. Esse problema, em El Alto, era solucionado através das redes de solidariedade aymará-vecinais:

O sacrificio dos vecinos foi muito grande porque (...) muitas famílias não tinham (...) o que comer. Alguns, porém, tinham, então dentro disso se estabeleceu uma solidariedade muito ampla. Isto é: (...) se eu não tenho, alguém, talvez o vecino, tenha. Então dava ao que não tinha. E em alguns lugares se fizeram as panelas comunitárias: (...) recolhiam todo tipo de alimentos (...) para fazer uma panela grande, ou uma sopa, e aí compartilhar entre (...) os que estavam nas barricadas, ou os que não tinham possibilidades de comida. Mas, também, muitas vezes nos demos conta de que em El Alto, como é migrante das províncias, (...) muitas famílias têm (...) semeaduras em suas comunidades, e em cada colheita recolhem algo de produto, chuño, batata. (...) Então isso também foi um meio de subsistência. (depoimento de vecino, El Alto; tradução livre).

E foi exatamente um problema de desabastecimento, no caso o de combustíveis, que desencadeou o momento mais trágico e o epitáfio do governo Sánchez de Lozada. Ao ordenar, nos dias 11 e 12 de outubro, que um comboio militar escoltasse caminhões-tanque de gasolina para recomposição dos postos em La Paz, o governo daria início ao momento mais trágico de todo o processo. Prevendo a possibilidade de enfrentamentos, mas disposto a aceitar os riscos para garantir o abastecimento, o governo afiançaria o comboio por meio da emissão do Decreto Supremo 27209 (Gómez, 2004), cujo artigo terceiro previa indenizações às famílias dos "eventuais" mortos resultantes do operativo.

A operação deflagrada pelo governo para a escolta a um comboio de caminhõestanque converteu-se em um confronto desenfreado e de violência inaudita. Os militares abriram caminho à bala entre os bloqueios, em um enfrentamento aberto onde se opu- 
seram rifles e metralhadoras contra dinamites e pedras, com alguns requintes de sadismo nas perseguições aos vecinos bairro adentro, resultando em aproximadamente 70 mortes e inviabilizando definitivamente qualquer possibilidade de diálogo.

O conflito então se agravaria e as diferentes demandas de todos os movimentos se reuniam agora em três, que passaram a ser conhecidas como "Agenda de outubro": as duas primeiras, de caráter estrutural, exigiam a nacionalização do gás e a convocação de uma Assembleia Constituinte; a última, e que assumia a frente do discurso, exigia a renúncia de Sánchez de Lozada, que, tarde demais, ainda emitiria o Decreto Supremo 27210 propondo um referendo para a discussão de por onde se exportaria o gás. Mas a ação tornada geral, com o apoio massivo dos bairros periféricos de La Paz, bairros estes formados a partir da mesma origem aymará de El Alto, estrangularia o governo que veria, em poucos dias, desfazer-se as coalizóes e apoios que lhe davam sua frágil estabilidade. Os bloqueios se multiplicaram por todos os departamentos, inviabilizando inclusive as comunicações via terrestre com os países vizinhos. Até mesmo a Câmara Agropecuária do Oriente, a organização de empresários agrários mais poderosa do país, lançou críticas ao massacre de El Alto.

As manifestações cresciam espontaneamente, movidas pelo ressentimento e pelo clamor por dignidade:

Ao dizer dignidade, ou ao dizer soberania, no sentido das lutas que houveram aqui, houve ressentimento, porque ninguém pode aceitar que uma pessoa morra injustamente, e à parte, a forma de organizar-se se baseou em que ninguém os convocou. Para que alguém os convocasse tinha que haver um líder, mas nesse momento (...) não havia líderes. As pessoas estavam conscientes, já era o momento de dizer 'basta de pilhagens', basta de (...) que outras pessoas venham e saqueiem o que é nosso. Já é o momento de que nós mesmos façamos a industrialização de nossos hidrocarbonetos. (depoimento de vecino, El Alto; tradução livre)

Acossado e sem apoios internos ou externos que lhe assegurassem a permanência no governo, o presidente Gonzalo Sánchez de Lozada renunciaria à presidência na noite de 16 de outubro, viajando no dia seguinte para os Estados Unidos, país onde residiu em sua infância e adolescência e onde vive hoje, molestado de tempos em tempos pelos pedidos de extradição exigidos por organizações de vítimas do massacre de El Alto e pelo atual governo boliviano.

\section{CONSIDERAÇÕES FINAIS}

Concordamos, a partir do que foi aqui apresentado, com a afirmativa de Chavéz (2006) de que na Bolívia as estruturas de mobilização estão baseadas nas estruturas organizativas, e aqui complementamos: estruturas organizativas territoriais. Ou seja, as formas de apropriação do espaço e as práticas que ocorrem sobre ele são tomadas como os referenciais para a ação coletiva. Isso pode parecer bastante óbvio quando nos referimos a movimentos tais como as juntas vecinales, uma vez que estes são formas de organização que partem diretamente do referencial territorial como eixo comum de associação. Mas é nossa interpretação de que, mais do que simplesmente constituírem-se tendo como referência algum tipo de associação territorial em sentido estrito, estes movimentos diferenciam-se pelo fato de basearem seu repertório discursivo e de ação nas práticas de uma territorialidade alternativa, contra-hegemônica. 
No que diz respeito à questão das juntas vecinales, há uma óbvia transposição ao meio urbano de outras culturas organizacionais. No caso do município de El Alto, ali se re-territorializam diferentes memórias organizativas, de longa (originárias) e de curta (sindicais) duração. Neste sentido, a questão territorial reveste-se de maior importância por ser uma instância na qual é possível reconhecermos presentes tanto a dimensão étnica quanto a dimensão classista daquele contexto, não assumindo nem descartando nem uma nem outra enquanto âmbitos exclusivos de análise. Díaz-Polanco (2004) nos recorda da importância da referência a estes dois âmbitos de análise no que diz respeito às sociedades latino-americanas, uma vez que é impossível que tracemos um perfil no qual qualquer uma delas se encontre isolada ou ausente. Se em algum momento houve exercícios de interpretação da realidade boliviana (mesmo, por extensão, da latino-americana) que priorizavam a dimensão classista da sociedade em detrimento da questão étnica - ou viceversa - o equívoco residia em especial na consideração de uma imutabilidade essencial da dimensão priorizada, uma propriedade metafísica, fosse essa característica aplicada ao proletariado, fosse ela aplicada aos grupos étnicos. Mas ambas as dimensões (etnia e classe) são constituídas por meio de processos históricos, e no caso das sociedades vitimadas pela colonização, influenciam-se mutuamente. Sendo assim, a questão a que Díaz-Polanco nos chama a atenção é para a necessária percepção da dimensão étnica presente na constituição de classe e da dimensão classista presente na constituição do grupo étnico. Lembremos aqui a concepção de Thompson de formação de classe:

O princípio teórico e metodológico básico do projeto histórico de Thompson é que as determinações objetivas - a transformação das relações de produção e das condições de trabalho jamais se impõem sobre 'alguma indefinida e indiferenciada matéria-prima da humanidade', impõem-se, pelo contrário sobre seres históricos, os portadores dos legados históricos, das tradiçôes e dos valores. (Wood, 2003, p.86)

Chamamos a atenção a este tema ao pensarmos a gênese da ação social em El Alto. Se muitas das determinações objetivas da ação ali presentes são relativas a questôes estruturais - portanto passíveis de uma análise classista - é inegável que há um conjunto de determinações subjetivas que se manifestam enquanto questôes de etnicidade, por meio de formas específicas de relação e de características culturais comuns.

As juntas vecinales nos mostram que frente às necessidades estruturais colocaram-se repertórios culturais, que re-territorializaram em meio urbano as estruturas socioterritoriais originárias andinas.

Assim, agrupamos alguns elementos presentes em todo este processo, cujo destaque consideramos necessário para melhor compreendê-lo:

a) Em relação à questão étnico-classista há, em primeiro lugar, que se destacar questóes estruturais particulares da Bolívia e que não são encontradas em outros contextos: aquelas oriundas das especificidades do processo colonial vivido naquele país. A permanência de estruturas sociais distintas em convivência direta, porém não harmoniosa, leva à formação daquilo que o sociólogo boliviano Rene Zavaleta definiu como "sociedade variegada", assim apresentada por Tapia:

A formação social variegada se caracteriza (...) por conter tempos históricos diversos, do qual uma expressão mais particularizada é a coexistência de vários modos de produção; a existência 
de várias formas políticas de matriz diversa e heterogênea, que se expressa na existência de um conjunto de estruturas locais de autoridade diversas entre si, e um Estado mais ou menos moderno e nacional, mas que não mantém relaçôes de organicidade com as anteriores e, em consequência, é um Estado mais ou menos aparente. (Tapia, 2002, p.310; tradução livre).

Tal condição acarreta sobre o mundo andino consequências negativas, como o fato de sua dificuldade de acesso a um universo dominado hegemonicamente pela sociedade de matriz ocidental, que é aquele onde se concentram os poderes político-institucional e econômico. Mas ao mesmo tempo, as desvantagens desse mundo ocidentalizado - que dia a dia prima cada vez mais por estratégias individualistas e pela perda do senso de comunidade - são os trunfos que a sociedade andina carrega consigo como memória de longa duração. As distintas lógicas de compreensão da vida e das relações sociais permitem aos andinos um maior senso de solidariedade e de responsabilidade mútua para com seus companheiros que logram construir redes de apoio e mobilização em dimensões que são impensáveis sob outras lógicas.

b) Ao resgatar a política do isolamento de instituições fechadas e excludentes para o calor das relações cotidianas, aqueles movimentos logram, também, criar um grau de conscientização que faz com que praticamente todos se vejam como partícipes dos processos vigentes. A política institucional vê perder a cada dia mais a sua credibilidade, dado que aposta na insensibilidade, nas articulações de ocasião, no descaso para com as demandas populares. Esse descrédito faz com que setores da sociedade - ao menos os setores desprivilegiados, isto é, populares - passem a apostar de forma mais direta na autogestão, nas práticas políticas de democracia plebiscitária e direta.

c) O conhecimento fundamental do território enquanto recurso estratégico é fundamental à ação destes movimentos, fato explicitado nos bloqueios do altiplano, e na própria posição singular em que se encontra a cidade de El Alto. Não à toa, a ocorrência do movimento recente (2006) pela chamada capitalía, que buscava trasladar a sede do governo a Sucre, certamente na intenção de afastá-la da urbe alteña e de sua capacidade de mobilização.

d) A nítida existência de uma perspectiva transescalar nas mobilizações observadas. As demandas, ainda que surgidas localmente, lançam questionamentos que encontram eco em espaços distintos, através de uma rede de articulaçôes formadas seja pelos processos migratórios, seja em razão das articulações sistêmicas que se projetam sobre o território boliviano.

O esforço de luta demonstrado nas ruas de El Alto é uma lição da força da gente mobilizada, da importância da conscientização diária e cotidiana, do reconhecimento da importância do resgate das lógicas comunitárias. $\mathrm{O}$ reconhecimento das estruturas organizacionais andinas abre as portas para a realização do "inédito-viável”, que segundo Freire:

É (...) algo que o sonho utópico sabe que existe, mas que só será conseguido pela práxis libertadora; (...) o "inédito-viável” é na realidade uma coisa inédita, ainda que não claramente conhecida e vivida, mas sonhada e quando se torna um "percebido destacado" pelos que pensam utopicamente, esses sabem, então, que o problema não é mais um sonho, que ele pode tornar-se realidade (Freire, 1992, p.206-7).
Marcelo Argenta Câmara é mestre em Geografia pela UFRGS; doutorando pelo Programa de Pós-Graduação em Geografia-UFF. Email: argentacamara@hotmail.com

Artigo recebido em março de 2011 e aprovado para publicação em abril de 2011. 


\section{REFERÊNCIAS BIBLIOGRÁFICAS}

CHAVÉZ, M. Sobre los "movimientos sociales” en Bolívia: Autonomía/Autoorganización y su relación con el Estado. In: CHAVÉZ, M. et al. Sujetos y Formas de la transformación politica en Bolivia. La Paz: Tercera Piel, 2006.

DÍAZ-POLANCO, H. El canon Snorri. Ciudad de México: UCM, 2004.

ESTERMANN, J. Filosofía Andina. La Paz: ISEAT, 2006.

GARCÍA, A. (Org.) Sociologia de los Movimientos Sociales en Bolivia. La Paz: Plural Editores, 2005.

GARFIAS, S.; MAZUREK, H. El Alto, desde una perspectiva poblacional. La Paz: CODEPO/IRD, 2005.

GÓMEZ, L. El Alto de pie - Una insurrección aymara en Bolivia. La Paz: Textos Rebeldes, 2004.

MAMANI, P. Geopoliticas indígenas. La Paz: CADES, $2005 \mathrm{a}$.

. Microgobiernos barriales. La Paz: CADES/IDIS-UMSA, 2005 b.

TAPIA, L. La producción del conocimiento local. La Paz: Muela del Diablo, 2002.

WOOD, E. M. Democracia contra capitalismo. São Paulo: Boitempo, 2003, 1995.

A B S T R A C T This paper analyzes the formation of urban social movements in the municipality of El Alto, Bolivia, emphasizing aspects of the re-territorialisation of aymara's and miner workers's social practices in Bolivian urban space. This analysis seeks to highlight the importance of these movements to the political processes experienced in that country over the past decade, highlighting in particular the events of 2003 known as Guerra do Gás (The Gas War). The methodology is the participatory research and its construction prioritizes the statements obtained from the very members of the movements analyzed. The conclusions highlight the importance of an analysis covering the different perspectives mentioned here for an effective understanding of social auctioning in Bolivia.

K E Y W O R D S Aymaras; Bolivia; El Alto; Juntas Vecinales; mine workers; social movements; urbanization. 